Review Article

\title{
Arm lymphedema after treatment of breast cancer: Etiology, diagnosis, and management
}

\begin{abstract}
Breast cancer related lymphedema $(\mathrm{BCRL})$ is a chronic debilitating condition seen after treatment of breast cancer. The overall incidence varies from $20 \%$ to $56 \%$ in all patients treated for breast cancer. Every patient is at a lifelong risk for BCRL and the risk goes on increasing as the followup period increases. Locoregional treatment including surgery or radiotherapy is the most common risk factor for development of arm lymphedema. There are two phases of arm lymphedema. There is increased fluid accumulation in the fluid phase of lymphedema which later on goes into the solid phase where fat and fibrotic tissue is deposited in the subcutaneous tissue. The treatment of BCRL is a challenge both for the patient and the treating surgeon and it needs multidisciplinary team work to be successful. Non-surgical treatment modalities include complete decongestive therapy (CDT) and pneumatic compression therapy. Surgery for BCRL is usually undertaken as a salvage modality after failure of conservative approaches. The surgical spectrum for BCRL varies from extensive excisional operations which were commonly done in the past to newer methods like suction assisted protein lipectomy, lymphatic reconstruction and vascular lymph node transfer (VLNT) using super-microsurgical techniques. There is no consensus regarding the preference of one procedure over other due to lack of randomised control trials. It is however suggested to do lymphovenous anastomosis and complete decongestive therapy for early cases in fluid phase; while patients in the solid phase may be treated with a combination of liposuction with CDT or VLNT alone.
\end{abstract}

Key words: Breast cancer-related lymphedema; liposuction; lymphovenous anastomosis; suction-assisted protein lipectomy; vascular lymph node transfer

\section{Introduction}

Breast cancer-related lymphedema (BCRL) is the most feared complication in patients undergoing treatment for breast cancer. It is a chronic debilitating condition and sometimes requires lifelong management. The main issues are significant swelling of limbs which disfigures the patient's body image and may lead to functional disability.[1]

Every breast cancer survivor is at a risk of developing arm lymphedema (LE). BCRL is a poorly understood disease and there is a lack of consensus for standardized treatment protocols. It is a challenge for the patient, family, as well as the multidisciplinary team treating them.

\section{Pathogenesis}

Arm LE results from abnormal accumulation of proteins

\begin{tabular}{|l|c|}
\hline \multicolumn{2}{|c|}{ Access this article online } \\
\hline \multirow{2}{*}{$\begin{array}{l}\text { Website: } \\
\text { www.asjo.in }\end{array}$} & Quick Response Code \\
\hline & \\
DOI: & \\
10.4103/2454-6798.173284 & \\
&
\end{tabular}

in the interstitial space due to interruption of normal lymphatic drainage channels. Initial swelling is due to excess fluid collection in subcutaneous tissues resulting in pitting edema. This is the initial fluid phase of LE. Longstanding LE leads to chronic accumulation of inflammatory fluids with fibrocyte and adipocyte activation similar to that seen in Crohn's disease and Graves' disease, resulting in deposition of fats in subcutaneous tissues with resultant nonpitting edema. This is known as the solid phase of LE. ${ }^{[2-5]}$ Longstanding exudation of proteins in the interstitial

\section{Ashish Goel, Juhi Agarwal, Sandeep Mehta, Kapil Kumar}

Department of Surgical Oncology, BLK Cancer Centre, New Delhi, India

Address for correspondence: Dr. Ashish Goel, Department of Surgical Oncology, BLK Cancer Centre, New Delhi, India.

E-mail: dr_ashishgoel@yahoo.com

This is an open access article distributed under the terms of the Creative Commons Attribution-NonCommercial-ShareAlike 3.0 License, which allows others to remix, tweak, and build upon the work non-commercially, as long as the author is credited and the new creations are licensed under the identical terms.

For reprints contact: reprints@medknow.com

How to cite this article: Goel A, Agarwal J, Mehta S, Kumar K. Arm lymphedema after treatment of breast cancer: Etiology, diagnosis, and management. Asian J Oncol 2015;1:77-83. 
space also triggers local fibrosis further impairing lymphatic circulation. ${ }^{[6,7]}$ These result into decreased distensibility of tissues around joints and limited range of movement. Axillary lymph node dissection (ALND) may further alter the lymph node transfer capacity. ${ }^{[8]}$

\section{Clinical Features}

The diagnosis of LE is based on clinical history, physical examination, and physiological measurement of limb size and volume. The most common symptoms are numbness $(62 \%)$ and pain (56\%) followed by stiffness $(42 \%)$ and limited range of motion (33\%). Arm swelling is seen in $25 \%$ cases. ${ }^{\mid 9]}$ Physical examination reveals peau d' orange, cutaneous, and subcutaneous fibrosis in skin and inability to grasp the skin of dorsum of second digit (Stemmer's Sign) [Figure 1]. All LE patients are at an increased risk of developing infection and cellulitis. The tissues have decreased the capacity of healing of minor wounds leading to microbial growth in the environment of excessive protein-rich lymph fluid.

Most patients suffer from lifelong anxiety, depression, and psychological distress which adversely affect the quality of life. Rarely, long-standing LE may be associated with increased incidence of malignancies, lymphangiosarcoma (Stewart Treves syndrome), Kaposi Sarcoma, or lymphoma..10,11]

\section{Incidence and Timing of Onset}

Patients with breast cancer may develop arm LE within days to up to decades after the completion of treatment. The overall incidence ranges from $20 \%$ to $56 \%$ across several studies, depending on the extent of surgery, adjuvant radiotherapy, and time of evaluation after completion of primary treatment..$^{[12-16]}$ In a longitudinal study of breast

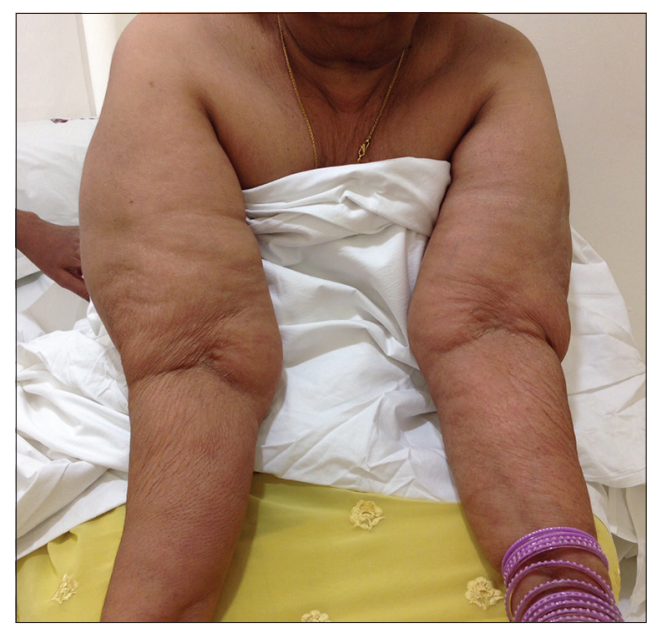

Figure 1: Right upper extremity lymphedema cancer surgery by Tasmuth et al., the incidence of LE was found to be $22 \%$ at 1 month and increased to $36 \%$ at 1 year after surgery. ${ }^{[17]}$ Similarly, Mortimer et al. suggested that arm edema increased over time after radiotherapy from $23 \%$ at 2 years to $45 \%$ at 15 years or more after treatment. ${ }^{[18]}$ The mean time for onset of BCRL after treatment is 14 months (range 2-92 months). ${ }^{[19]}$ It has been suggested that $75 \%$ of BCRL cases occur within the $1^{\text {st }}$ year after surgery and $90 \%$ within 3 years. With every year of follow-up, there is an annual increment of LE by $1 \%$ in the same patient. ${ }^{[20,21]}$

\section{Etiology}

The most common cause for the development of arm edema is breast cancer treatment including ALND, modified radical mastectomy with axillary clearance, breast conservation surgery (BCS), and adjuvant radiation therapy (RT). Surgical aggressiveness has always been considered as a major risk factor for the development of LE in breast cancer patients. The incidence of postsurgery LE is $24-49 \%$ after MRM and 4-28\% after BCS. It is understood that patients undergoing mastectomy have more advanced disease and, therefore, need more aggressive axillary dissection leading to higher chance of arm LE. ${ }^{[22]}$ In the study by Johansson et al., patients with large tumor size were found to be associated with higher incidence of LE; probably due to aggressive axillary surgery in this group. ${ }^{[23]}$

Patients who undergo axillary dissection are at a higher risk of developing LE as compared to patients with no or minimal axillary treatment. In a meta-analysis of 72 studies, the incidence of $L E$ was found to occur in $19.9 \%$ patients after ALND. ${ }^{[24]}$ Once axillary lymph nodes are removed by dissection, the main lymphatic collectors of axilla have no path to continue the lymphatic drainage; leading to a functional overload of lymphatic system with a collection of fluid into subcutaneous tissues. ${ }^{\mid 25]}$ Sentinel lymph node biopsy (SLNB) avoids complete axillary dissection and thus decreases the risk of longstanding LE formation. In the study by Miller et al., the cumulative incidence of LE was as low as $2.19 \%$ with SLNB alone compared to $19.3 \%$ with ALND. The risk factors associated with BCRL were ALND, number of lymph nodes excised, use of adjuvant RT, higher body mass index, and old age. ${ }^{[26]}$ In the systematic review by DiSipio et al., the incidence of LE with ALND was four times more than with SLNB $\left(19.3 \%\right.$ vs. 5.6\%). ${ }^{[24]}$ The number of lymph nodes involved pathologically is an important factor for the development of LE, the possibility of arm problems may increase relative to every lymph node excised. ${ }^{\mid 27,28]}$

Use of any nodal irradiation whether in combination with ALND or SLNB increases the risk of BCRL. In the study by Miller 
et al., the incidence of LE was $30.1 \%$ with a combination of ALND and RT compared to $19.3 \%$ with ALND alone. ${ }^{[26]}$ In the prospective study by Warren et al., the risk of LE increased to seven times after postoperative irradiation to supraclavicular fossa (SCF) or axilla compared to breast or chest wall irradiation alone. There was no difference in LE risk between SCF and SCF + axilla $(21.9 \%$ vs. $21.1 \%, P=0.96) \cdot{ }^{[29]}$ A combination of axillary dissection and axillary radiation should, therefore, be avoided whenever feasible to avoid LE. ${ }^{[30]}$

Although locoregional treatment is a major risk factor for the development of LE, the impact of systemic therapy remains controversial. In a study by Cariati et al., patients who received taxanes in adjuvant setting were three times more likely to develop LE compared to patients who did not receive chemotherapy. No such increase was observed when taxanes were administered in neoadjuvant setting. ${ }^{|31|}$ Residual lymph nodes after neoadjuvant chemotherapy predict for greater risk of LE and should be carefully monitored for development of arm swelling on the completion of treatment. ${ }^{[32]}$ In another study, although adjuvant chemotherapy with docetaxel was significantly associated with higher incidence of mild arm swelling compared to patients who did not receive any chemotherapy or taxane-based chemotherapy; this did not translate into a higher chance of development of subsequent LE. ${ }^{[33]}$

Obesity, sedentary lifestyle, postoperative infection; phlebitis, cellulitis, and erysipelas of upper limb, prolonged seroma, and scar maturation have been suggested as other important risk factors for BCRL. ${ }^{[25,34-37]}$ Other patient-related factors include old age, coexisting arthritis, hypertension, and diabetes.

\section{Stages of Breast Cancer-Related Lymphedema}

Most patients present with initial soft pitting edema in the affected extremity. This may progress to nonpitting edema with resultant fibrosis and hardening of the skin or subcutaneous tissues. Late changes include irreversible interstitial fibrosis and atrophy of smooth muscle cells within lymphatic vessel walls. The International Society of Lymphology has classified LE into four stages, graded as stage 0 with no arm swelling to stage 3 with most severe signs and symptoms based on volume differences between the affected and contralateral limb (mild $\leq 20 \%$ increase; moderate $=$ $20-8 \%$ increase, severe $\geq 38 \%$ increase) [Table 1]. ${ }^{[38]}$ Similar staging has been described by Campisi et al. based on clinical approach toward management [Table 2]. ${ }^{\text {[9] }}$
Table 1: Lymphedema staging by international society of lymphology

\begin{tabular}{l}
\hline Clinical stage \\
0 - A subclinical stage - Swelling is not seen despite underlying changes in \\
lymphatic system \\
I - Initial stage of swelling which can be transient; simple elevation can \\
alleviate swelling \\
II - Swelling is constant and pitting without resolution using elevation \\
III - Tissue has become hard and fibrotic with associated skin changes \\
\hline
\end{tabular}

Table 2: Lymphedema staging by Campisi et al

\begin{tabular}{l}
\hline Stage la - Latent lymphedema \\
Stage Ib - Reversible on limb elevation \\
Stage II - Mild persistence on elevation \\
Stage III - Persistent swelling with lymphangitis \\
Stage IV - Fibrotic changes with column like limb \\
Stage V - Elephantiasis deformity with warts \\
\hline
\end{tabular}

\section{Clinical Assessment}

Measurement of arm circumference at specified distance from anatomic landmarks is currently the most common method for assessing changes in limb girth in patients with breast cancer. Any change in arm circumference by $2 \mathrm{~cm}$ or more between affected and unaffected limb is labeled as LE. ${ }^{[40,41]}$ Perometry is more accurate and uses infrared light and optoelectronic sensors to assess limb volume changes. Any difference of $10 \%$ or $200 \mathrm{ml}$ or more from baseline compared to contralateral limb is labeled as LE. ${ }^{[40]}$

Water displacement method is the most sensitive technique to assess changes in limb volume, especially in patients with varying limb shapes. It is, however, contraindicated in patients with skin ulcers or cellulitis. ${ }^{\mid 40,41]}$ Bioelectric impedance spectroscopy (BIS) and tissue dielectric constants (TDC) have been used as accurate assessment tools for LE, especially in research protocols. BIS estimates the extracellular fluid volume by measuring the resistance of body tissues to low alternating currents at various frequencies. ${ }^{[42]}$ TDC uses a probe connected to a control unit which displays tissue water changes when placed over the skin. ${ }^{[42]}$ Both these techniques correlate well with limb volume changes and can be used for assessing patients with breast cancer at risk of LE. ${ }^{[42,43]}$ Objective assessment of patient symptoms and clinical signs of LE play a crucial role in clinical practice. It is very important to rule out any tumor recurrence before treating LE.

\section{Treatment of Breast Cancer-Related Lymphedema}

\section{Complete decongestive therapy}

Complete decongestive therapy (CDT) performed under the supervision of a trained LE nurse or physiotherapist is 
currently the gold standard of care for the management of arm $\mathrm{LE}^{[38,44]}$ The goal of CDT is to move lymphatic fluid to an area where it can drain and subsequently help reduce arm swelling. The various components of CDT include manual lymphatic drainage, use of compression bandage and garments, regular arm exercises, and meticulous skin care and hygiene. ${ }^{[45,46]}$ The patients need to follow a strict and structured lifelong and self-motivated schedule of arm exercises. It is important for the patient and her family to understand signs of acute inflammation to identify the development of cellulitis and facilitate prompt treatment for the same and prevent further impairment of lymphatic transport.

\section{Pneumatic compression therapy}

Newer modalities include the use of pneumatics, aqua lymphatic therapy, and low-level lasers as adjunctive methods. Intermittent pneumatic compression consists of a sleeve garment with different chambers and compartments. This applies pressure in a regulated manner and helps reduce arm swelling. ${ }^{[47]}$ Aqua lymphatic therapy uses the viscosity of water to provide resistance to body movement to reduce arm volume. ${ }^{[48]}$ Low-level laser therapy is still not available universally and is costly.

\section{Surgical treatment}

There has been significant research in surgical techniques for reducing arm swelling; including excisional operations, liposuction, lymphatic reconstruction, and lymph node transfers with super microvascular surgery. Surgery is still not considered the first-line therapy and is offered only as a salvage modality after failure of conservative approaches. All patients need to understand the need for lifelong use of compression garments even after successful surgical reduction of arm swelling.

There are no comparative studies to suggest the superiority of one technique over another. Cormier et al. in a systematic review of twenty studies did not show a clear benefit of surgery over CDT for BCRL. ${ }^{[49]}$ There is also a lack of standardization of literature for lymphovenous anastomosis (LVA) and vascularized lymph node transfer (VLNT). Recently, microvascular surgical techniques have evolved to become more and more effective and less invasive..$^{[50,51]}$

\section{Excisional surgery}

The earliest excision procedure was described by Charles in 1912 as a debulking surgery to remove skin and deep tissues followed by split thickness skin graft cover over the defect. Skin grafts were often harvested from the excised tissues. The main complications include destruction of remnant lymphatics, gross esthetic deformity, and early return of LE. Currently, it is indicated only in late stage elephantiasis. ${ }^{[22,53]}$
Another method of lymphatic tissue debulking was described by Sistrunk in 1918, the modified Kondoleon procedure. It involved partial excision of an elliptical island of skin and subcutaneous tissues and covering the defect by local flaps. It was initially described for end-stage LE cases with extensive skin keratosis. The aim of the procedure was to excise the diseased portion of tissue and achieve physiological connection between superficial and deep lymphatics to restore lymphatic circulation in affected extremity. ${ }^{[4,55]}$

\section{Suction-assisted protein lipectomy}

Longstanding LE of 15-20 years duration induces the process of adipogenesis; therefore, CDT alone does not work in reducing this fat deposit. Suction-assisted protein lipectomy (SAPL) is beneficial for the removal of excess fatty tissue using power-assisted liposuction. Since SAPL does not address the pathophysiology of LE, these patients need to continue using compression garments to prevent relapse of swelling. Short-term outcomes have shown significant reduction of arm volume up to $101 \%$ at 1 year. ${ }^{[56]}$ Further prospective studies have suggested improved outcomes at follow-up of 8 and 15 years with significantly reduced incidence of cellulitis by up to $75 \%{ }^{|56-58|}$

\section{Lymphovenous anastomosis}

LVA involves establishing a connection between lymphatic vessels and small adjacent venules and thus allowing excess lymph fluid to flow across the obstructed vessels into the venous system. Small subdermal lymphatics are selected as afferent channels due to better compliance. Subcutaneous venules have little or no back flow; being a low-pressure system compared to larger veins and thus create a favorable gradient of lymphaticovenous transport. In a prospective study by Chang et al., symptomatic improvement was noted in $96 \%$ patients, quantitative improvement in $74 \%$ cases, and a mean overall volume reduction of $42 \%$ at 12 months follow-up. ${ }^{\text {[59] }}$ Effect of LVA may not be longstanding due to further blockade of these anastomotic channels. The main challenges are the identification of small venules and lymphatics in subdermal tissues. This is facilitated by the use of lymphazurin lymphangiography and laser angiography using ICG. Super microsurgical techniques are involved as most vessel diameters range from 0.1 to $0.6 \mathrm{~mm}$ in diameter. ${ }^{[00]}$ Patients in fluid phase of LE with intact lymphatic vessel integrity and minimal tissue fibrosis are most suitable for LVA.

\section{Vascularized lymph node transfer}

The aim of VLNT is to bring vascularized tissue along with healthy lymph nodes into sites affected by LE. Physiologically, it works as a lymphatic pump allowing for drainage of excess fluid into the lymphatic system. It also induces lymphangiogenesis by the release of vascular endothelial 
growth factor-C from transplanted nodes and promote reconnection of lymphatics. Various immunologic factors also come into play to induce local immunity. The procedure involves a microsurgical transfer of lymph nodes along with its arteriovenous supply from a donor site such as groin or neck to recipient sites in axilla or more distally in arm or forearm to restore lymphatic flow. The groin is the preferred donor site, using a superolateral group of lymph nodes draining the lower abdomen, as they lead to minimal chance of inducing iatrogenic lower limb edema. The scar is well hidden and has sufficient soft tissue for the cover of defect. ${ }^{[61,62]}$ Submental lymph nodes based on submental vessels or supraclavicular lymph nodes based on transverse cervical vessels may also be chosen as donor sites. ${ }^{[63,64]} \mathrm{At}$ the recipient site, axillary scar is removed and all fibrotic and avascular tissues are dissected and adhesions released until healthy fat is reached. A microvascular anastomosis is performed between the vessels of lymph nodes with recipient vessels. The indications of VLNT include total occlusion of lymphatic channels on lymphangiography, LE of more than 12 weeks duration, absence of any acute episode of cellulitis, and grade 2 LE. ${ }^{[69]}$ The mean volume reduction of arm LE in patients with BCRL after VLNT ranges from 31\% to $56 \%$ across several studies. ${ }^{[65-69]}$ The major disadvantage of VLNT is potential donor site morbidity. Sentinel node scintigraphy with reverse mapping and magnetic resonance lymphangiography at recipient site may be used to select suitable lymph node groups for transfer. ${ }^{[70]}$ Another method to perform VLNT is by incorporating it along with deep inferior epigastric perforator flap harvested for secondary breast reconstruction. ${ }^{[71]} \mathrm{A}$ distal site tissue transfer at wrist or elbow is also feasible to create a local lymphovenous shunt. Any operative procedure in the axilla wherein severe fibrosis is encountered may make it difficult for microvascular anastomosis. Shesol et al. postulated the "stop cock theory" based on rebound circulation in blocked lymphatics which makes it feasible to do nonanatomic distant placement of vascularized lymph nodes, which returns the lymph to the "lymphatic collectors." This leads to a bidirectional lymphatic flow at wrist and elbow. ${ }^{[72]}$

\section{Conclusion}

With advances in the management of breast cancer and longer survival, more patients are likely to develop long-term sequelae of breast cancer treatment and arm LE. A comprehensive LE care would be required for these patients including early diagnosis and treatment. At present, complete decongestive therapy is the gold standard for the treatment of LE, but it is limited in effect for fluid phase only. With advances in microsurgical techniques, more and more patients are likely to benefit with newer surgical modalities; both in terms of reduction in limb circumference and volume and improvement in the quality of life, even in solid phase LE. The ideal surgical treatment should be one which repairs or re-establishes lymphatic function, provides a complete and permanent improvement in arm swelling with minimal procedure-related morbidity and no need to wear compression garments. Although there are no head-to-head comparative studies to suggest the best surgical approach, patients in fluid phase of edema are more likely to benefit from LVA and CDT, whereas patients in the late phase are more likely to benefit from liposuction in combination with CDT or VLNT alone.

\section{Financial support and sponsorship}

Nil.

\section{Conflicts of interest}

There are no conflicts of interest.

\section{References}

1. Warren AG, Brorson H, Borud LJ, Slavin SA. Lymphedema: A comprehensive review. Ann Plast Surg 2007;59:464-72.

2. Ryan TJ. Lymphatics and adipose tissue. Clin Dermatol 1995;13:493-8.

3. Erickson VS, Pearson ML, Ganz PA, Adams J, Kahn KL. Arm edema in breast cancer patients. J Natl Cancer Inst 2001;93:96-111.

4. Brorson H. From lymph to fat: Liposuction as a treatment for complete reduction of lymphedema. Int J Low Extrem Wounds 2012;11:10-9.

5. Brorson H, Ohlin K, Olsson G, Karlsson MK. Breast cancer-related chronic arm lymphedema is associated with excess adipose and muscle tissue. Lymphat Res Biol 2009;7:3-10.

6. Burt J, White G, editors. Lymphedema. In: Lymphedema: A Breast Cancer Patient's Guide to Prevention and Healing. New York: Hunter House Publishers; 1999. p. 2-23.

7. Brennan MJ, DePompolo RW, Garden FH. Focused review: Postmastectomy lymphedema. Arch Phys Med Rehabil 1996;77 3 Suppl: S74-80.

8. Aboul-Enein A, Eshmawy I, Arafa S, Abboud A. The role of lymphovenous communication in the development of postmastectomy lymphedema. Surgery 1984;95:562-6.

9. Maunsell E, Brisson J, Deschênes L. Arm problems and psychological distress after surgery for breast cancer. Can J Surg 1993;36:315-20.

10. Ruocco V, Schwartz RA, Ruocco E. Lymphedema: An immunologically vulnerable site for development of neoplasms. J Am Acad Dermatol 2002;47:124-7.

11. Sharma A, Schwartz RA. Stewart-Treves syndrome: Pathogenesis and management. J Am Acad Dermatol 2012;67:1342-8.

12. Petrek JA, Heelan MC. Incidence of breast carcinoma-related lymphedema. Cancer 1998;83 12 Suppl American:2776-81.

13. McCredie MR, Dite GS, Porter L, Maskiell J, Giles GG, Phillips KA, et al. Prevalence of self-reported arm morbidity following treatment for breast cancer in the Australian Breast Cancer Family Study. Breast 2001;10:515-22.

14. Kissin MW, Querci della Rovere G, Easton D, Westbury G. Risk of lymphoedema following the treatment of breast cancer. Br J Surg 1986;73:580-4.

15. Schrenk P, Rieger R, Shamiyeh A, Wayand W. Morbidity following sentinel lymph node biopsy versus axillary lymph node dissection for patients with breast carcinoma. Cancer 2000;88:608-14.

16. Gerber L, Lampert M, Wood C, Duncan M, D’Angelo T, Schain W, et al. Comparison of pain, motion, and edema after modified radical 
mastectomy vs. local excision with axillary dissection and radiation. Breast Cancer Res Treat 1992;21:139-45.

17. Tasmuth T, von Smitten K, Kalso E. Pain and other symptoms during the first year after radical and conservative surgery for breast cancer. Br J Cancer 1996;74:2024-31.

18. Mortimer PS, Bates DO, Brassington HD, Stanton AW, Strachan DP, Levick JR. The prevalence of arm oedema following treatment for breast cancer. Q J Med 1996;89:377-80.

19. Werner RS, McCormick B, Petrek J, Cox L, Cirrincione C, Gray JR, et al. Arm edema in conservatively managed breast cancer: Obesity is a major predictive factor. Radiology 1991;180:177-84.

20. Rockson SG. Precipitating factors in lymphedema: Myths and realities. Cancer 1998;83 12 Suppl American:2814-6.

21. Petrek JA, Senie RT, Peters M, Rosen PP. Lymphedema in a cohort of breast carcinoma survivors 20 years after diagnosis. Cancer 2001;92:1368-77.

22. Warren AG, Brorson H, Borud LJ, Slavin SA. Lymphedema: A comprehensive review. Ann Plast Surg 2007;59:464-72.

23. Johansson K, Ohlsson K, Ingvar C, Albertsson M, Ekdahl C. Factors associated with the development of arm lymphedema following breast cancer treatment: A match pair case-control study. Lymphology 2002;35:59-71.

24. DiSipio T, Rye S, Newman B, Hayes S. Incidence of unilateral arm lymphoedema after breast cancer: A systematic review and meta-analysis. Lancet Oncol 2013;14:500-15.

25. Rett MT, Lopes MC. Risk factors for lymphedema. Rev Bras Mastologia 2002;12:39-42.

26. Miller CL, Specht MC, Skolny MN, Horick N, Jammallo LS, O'Toole J, et al. Risk of lymphedema after mastectomy: Potential benefit of applying ACOSOG Z0011 protocol to mastectomy patients. Breast Cancer Res Treat 2014;144:71-7.

27. Liljegren G, Holmberg L. Arm morbidity after sector resection and axillary dissection with or without postoperative radiotherapy in breast cancer stage I. Results from a randomised trial. Uppsala-Orebro Breast Cancer Study Group. Eur J Cancer 1997;33:193-9.

28. Kiel KD, Rademacker AW. Early-stage breast cancer: Arm edema after wide excision and breast irradiation. Radiology 1996;198:279-83.

29. Warren LE, Miller CL, Horick N, Skolny MN, Jammallo LS, Sadek BT, et al. The impact of radiation therapy on the risk of lymphedema after treatment for breast cancer: A prospective cohort study. Int J Radiat Oncol Biol Phys 2014;88:565-71.

30. Deo SV, Ray S, Rath GK, Shukla NK, Kar M, Asthana S, et al. Prevalence and risk factors for development of lymphedema following breast cancer treatment. Indian J Cancer 2004;41:8-12.

31. Cariati M, Bains SK, Grootendorst MR, Suyoi A, Peters AM, Mortimer P, et al. Adjuvant taxanes and the development of breast cancer-related arm lymphoedema. Br J Surg 2015;102:1071-8.

32. Specht MC, Miller CL, Skolny MN, Jammallo LS, O’Toole J, Horick N, et al. Residual lymph node disease after neoadjuvant chemotherapy predicts an increased risk of lymphedema in node-positive breast cancer patients. Ann Surg Oncol 2013;20:2835-41.

33. Swaroop MN, Ferguson CM, Horick NK, Skolny MN, Miller CL, Jammallo LS, et al. Impact of adjuvant taxane-based chemotherapy on development of breast cancer-related lymphedema: Results from a large prospective cohort. Breast Cancer Res Treat 2015;151:393-403.

34. Bergmann A, Mattos IE, Koifman RJ. Diagnosis of lymphedema: Analysis of the methods employed in upper limb evaluation after axillary lymphadenectomy for treatment of breast cancer. Rev Bras Cancerol 2004;50:311-20.

35. Rezende LF, Pedras FV, Ramos CD, Gurgel MS. Evaluation of lymphatic compensation in breast cancer post operative axillary dissection through lymphoscintigraphy. J Vasc Bras 2008;7:370-5.

36. Hayes SC, Janda M, Cornish B, Battistutta D, Newman B. Lymphedema after breast cancer: Incidence, risk factors, and effect on upper body function. J Clin Oncol 2008;26:3536-42.
37. Pain SJ, Vowler S, Purushotham AD. Axillary vein abnormalities contribute to development of lymphoedema after surgery for breast cancer. Br J Surg 2005;92:311-5.

38. International Society of Lymphology. The diagnosis and treatment of peripheral lymphedema: 2013 Consensus Document of the International Society of Lymphology. Lymphology 2013;46:1-11.

39. Campisi C, Boccardo F. Microsurgical techniques for lymphedema treatment: Derivative lymphatic-venous microsurgery. World J Surg 2004;28:609-13.

40. Armer JM. The problem of post-breast cancer lymphedema: Impact and measurement issues. Cancer Invest 2005;23:76-83.

41. Armer JM, Stewart BR. A comparison of four diagnostic criteria for lymphedema in a post-breast cancer population. Lymphat Res Biol 2005;3:208-17.

42. Ward LC, Czerniec S, Kilbreath SL. Quantitative bioimpedance spectroscopy for the assessment of lymphoedema. Breast Cancer Res Treat 2009;117:541-7.

43. Mayrovitz HN, Davey S, Shapiro E. Local tissue water changes assessed by tissue dielectric constant: Single measurements versus averaging of multiple measurements. Lymphology 2008;41:186-8.

44. Position Statement of the National Lymphedema Network. Available from: http://www.lymphnet.org/category/position-papers. [Last accessed on 2014 Mar 05].

45. Armer JM, Hulett JM, Bernas M, Ostby P, Stewart BR, Cormier JN. Best practice guidelines in assessment, risk reduction, management, and surveillance for post-breast cancer lymphedema. Curr Breast Cancer Rep 2013;5:134-144.

46. Cheifetz O, Haley L; Breast Cancer Action. Management of secondary lymphedema related to breast cancer. Can Fam Physician 2010;56:1277-84.

47. Feldman JL, Stout NL, Wanchai A, Stewart BR, Cormier JN, Armer JM. Intermittent pneumatic compression therapy: A systematic review. Lymphology 2012;45:13-25.

48. Tidhar D, Katz-Leurer M. Aqua lymphatic therapy in women who suffer from breast cancer treatment-related lymphedema: A randomized controlled study. Support Care Cancer 2010;18:383-92.

49. Cormier JN, Rourke L, Crosby M, Chang D, Armer J. The surgical treatment of lymphedema: A systematic review of the contemporary literature (2004-2010). Ann Surg Oncol 2012;19:642-51.

50. Damstra RJ, Voesten HG, van Schelven WD, van der Lei B. Lymphatic venous anastomosis (LVA) for treatment of secondary arm lymphedema. A prospective study of 11 LVA procedures in 10 patients with breast cancer related lymphedema and a critical review of the literature. Breast Cancer Res Treat 2009;113:199-206.

51. Granzow JW, Soderberg JM, Kaji AH, Dauphine C. Review of current surgical treatments for lymphedema. Ann Surg Oncol 2014;21:1195-201.

52. Cormier JN, Rourke L, Crosby M, Chang D, Armer J. The surgical treatment of lymphedema: A systematic review of the contemporary literature (2004-2010). Ann Surg Oncol 2012;19:642-51.

53. Charles H. Elephantiasis of the leg. In: Latham A, English TC, editors. A System of Treatment. Vol. 3. London: Churchill; 1912.

54. Sistrunk WE. Modification of the operation for elephantiasis. J Am Med Assoc 1918;71:800-3.

55. Savage RC. The surgical management of lymphedema. Surg Gynecol Obstet 1984;159:501-8.

56. Granzow JW, Soderberg JM, Kaji AH, Dauphine C. An effective system of surgical treatment of lymphedema. Ann Surg Oncol 2014;21:1189-94.

57. Brorson H, Freccero C, Ohlin K, Svensson B. Liposuction of postmastectomy arm lymphedema completely removes excess volume: A 15 year study. Lymphology 2010;43 Suppl:108-10.

58. Brorson H, Ohlin K, Olsson G, Svensson B. Liposuction normalized elephantiasis of the leg: A prospective study. Eur J Lymphol 2007;17:8.

59. Chang DW, Suami H, Skoracki R. A prospective analysis of 100 consecutive lymphovenous bypass cases for treatment of extremity lymphedema. Plast Reconstr Surg 2013;132:1305-14. 
60. Chang DW. Lymphaticovenular bypass for lymphedema management in breast cancer patients: A prospective study. Plast Reconstr Surg 2010;126:752-8.

61. Pons G, Masia J, Loschi P, Nardulli ML, Duch J. A case of donor-site lymphoedema after lymph node-superficial circumflex iliac artery perforator flap transfer. J Plast Reconstr Aesthet Surg 2014;67:119-23.

62. Viitanen TP, Mäki MT, Seppänen MP, Suominen EA, Saaristo AM. Donor-site lymphatic function after microvascular lymph node transfer. Plast Reconstr Surg 2012;130:1246-53.

63. Cheng MH, Lin CY, Patel K. A prospective assessment of anatomic variability of the submental vascularized lymph node flap. Plast Reconstr Surg 2014;134:33.

64. Yeo MS, Lim SY, Kiranantawat K, Ciudad P, Chen HC. A comparison of vascularized cervical lymph node transfer with and without modified Charles' procedure for the treatment of lower limb lymphedema. Plast Reconstr Surg 2014;134:171e-2e.

65. Lin CH, Ali R, Chen SC, Wallace C, Chang YC, Chen HC, et al. Vascularized groin lymph node transfer using the wrist as a recipient site for management of postmastectomy upper extremity lymphedema. Plast Reconstr Surg 2009;123:1265-75.

66. Saaristo AM, Niemi TS, Viitanen TP, Tervala TV, Hartiala P, Suominen EA. Microvascular breast reconstruction and lymph node transfer for postmastectomy lymphedema patients. Ann Surg 2012;255:468-73.

67. Gharb BB, Rampazzo A, Spanio di Spilimbergo S, Xu ES, Chung KP, Chen HC. Vascularized lymph node transfer based on the hilar perforators improves the outcome in upper limb lymphedema. Ann Plast Surg 2011;67:589-93.

68. Becker C, Assouad J, Riquet M, Hidden G. Postmastectomy lymphedema: Long-term results following microsurgical lymph node transplantation. Ann Surg 2006;243:313-5.

69. Cheng MH, Chen SC, Henry SL, Tan BK, Lin MC, Huang JJ. Vascularized groin lymph node flap transfer for postmastectomy upper limb lymphedema: Flap anatomy, recipient sites, and outcomes. Plast Reconstr Surg 2013;131:1286-98.

70. Dayan JH, Dayan E, Smith ML. Reverse lymphatic mapping: A new technique for maximizing safety in vascularized lymph node transfer. Plast Reconstr Surg 2015;135:277-85.

71. Nguyen AT, Chang EI, Suami H, Chang DW. An algorithmic approach to simultaneous vascularized lymph node transfer with microvascular breast reconstruction. Ann Surg Oncol 2015;22:2919-24.

72. Shesol BF, Nakashima R, Alavi A, Hamilton RW. Successful lymph node transplantation in rats, with restoration of lymphatic function. Plast Reconstr Surg 1979;63:817-23. 